\section{Estudo comparativo entre diversas técnicas de confecção de modelo experimental de sinusite inflamatória em coelhos}

\author{
Henrique Olival Costa ${ }^{1}$, Giulliano Enrico Ruschi \\ e Luchi ${ }^{2}$, Artbur Guilerme Augusto ${ }^{3}$, Marilia \\ Castró, Flavia Coelho de Souza ${ }^{5}$
}

\section{Resumo / Summary}

\begin{abstract}
A
criação de modelos de estudo das rinossinusites é necessária para compreensão de seus aspectos fisiopatológicos. Objetivo: Sugerimos neste estudo estabelecer um modelo experimental fidedigno, reproduzível e consistente para a rinossinusite inflamatória sem uso de inoculação de agentes infecciosos em coelhos. Tipo de Estudo: Experimental. Material e Método: Foram utilizados 20 coelhos neste estudo. Os animais foram submetidos a 4 intervenções diferentes: colocação de tampão de esponja unilateral, obliteração unilateral de óstio nasal com cianoacrilato, instilação unilateral de antígenos em seio maxilar e instilação de sangue em cavidade maxilar unilateral. Os animais foram acompanhados até 15 dias do início do estudo e ao final do período de seguimento foram anestesiados e sacrificados. Os seios maxilares foram avaliados histologicamente e os resultados comparados com os seios maxilares contralaterais para controle e entre os grupos de intervenção. Resultados: Todos os animais do estudo desenvolveram rinorréia amarelada unilateral até o $15^{\circ}$ dia de acompanhamento. Apenas os animais que receberam sangue não apresentaram alterações histológicas compatíveis com rinossinusite purulenta. Conclusões: $\mathrm{O}$ uso de esponja e cola para obstrução do óstio meatal e a aplicação de toxóide são eficientes como produtores de modelo de rinossinusite. A aplicação de sangue no antro não produz os mesmos resultados.
\end{abstract}

Comparative study of several sinusitis experimental modelling techniques in rabbits

Palavras-chave: coelhos, experimental, modelo, rinossinusite, sinusite.

Keywords: rabbits, experimental, model, rhinosinusitis, sinusitis.

\begin{abstract}
$\mathrm{E}$ are needed. Aim: to define a reliable, solid and reproducible experimental model for inflammatory rhinosinusitis with no innoculation of infectious agents in rabbits. Study design: Experimental. Material and Method: Twenty 20 rabbits were divided into 4 groups submitted to 4 different interventions: the placement of a unilateral nasal fossa sponge, unilateral obliteration of the nasal ostium with cyanoacrylate, unilateral placement of antigens in the maxillary cavity and unilateral placement of blood in the maxillary cavity. The animals were monitored for 15 days and then anesthetized and sacrificed; the maxillary sinuses were evaluated histologicaly and results were compared with controls and between the intervention groups. Conclusion: Sponje and glue as agents of meatal obstruction and toxoid aplied in the antrum are efficient as methods for rhinosinusitis modeling. Blood was not efficient in producing sinusitis.
\end{abstract}

\footnotetext{
${ }^{1}$ Otorrinolaringologista, Cirurgião de Cabeça e Pescoço; Doutor em Otorrinolaringologia; Prof. Adjunto do Depto. de Otorrinolaringologia da Santa Casa de São Paulo, Coordenador do programa de Pós-Graduação em ORL da Santa Casa de São Paulo.

2 Otorrinolaringologista, Mestrando em ORL pela Santa Casa de São Paulo, Médico.

3 Professor Doutor, Professor do programa de pós-graduação em ORL da Santa Casa de São Paulo. ${ }^{4}$ Patologista da Santa Casa de São Paulo.

${ }^{5}$ Médica veterinária, Mestre em ciências da saúde pela UNIFESP.

Faculdade de Ciências Médicas da Santa Casa de São Paulo.

Endereço para correspondência: Rua Prof. Arthur Ramos 183 30 andar São Paulo SP 01454-00. FAPESP.

Este artigo foi submetido no SGP (Sistema de Gestão de Publicações) da RBORL em 12 de julho de 2006. cod. 2722

Artigo aceito em 30 de março de 2007.
} 


\section{INTRODUÇÃO}

A prevalência de doenças infecto-inflamatórias das vias respiratórias é extremamente alta na população geral (cerca de $25 \%$ da população tem rinite alérgica e há uma média de 4 gripes ao ano para cada habitante, e um total de 680.000 rinossinusites agudas ao ano, somente no Brasil) e o custo dos medicamentos utilizados é elevado (o custo médio do tratamento de uma rinossinusite aguda é de $R \$ 20,00$. Nos EUA se estima que os gastos com esta enfermidade seja de até 5 bilhões de dólares/ano) ${ }^{1,2}$.

O tratamento das rinossinusites pode ter diversas linhas de conduta, estendendo-se desde o uso de antiinflamatórios tópicos e sistêmicos até a instilação de substâncias adstringentes, uso de fluidificantes e anti-sépticos até a administração de antibióticos.

Além da natural dificuldade de categorizar os diversos processos patológicos regionais, levando a se colocar na mesma classe infecções processos alérgicos e alterações anatômicas, há a possibilidade de co-existência de fatores patogênicos em um mesmo caso.

Essa situação leva a muitas impropriedades no estudo clínico das rinossinusites.

Isso posto, entendemos que fica exposta a necessidade de se criar modelos experimentais adequados para o estudo clínico das rinossinusites.

A literatura mundial tem apresentado diversas tentativas de modelação em animais, sendo os estudos com roedores os mais freqüentes. Aparentemente há uma razão fisiopatológica para que isto ocorra, visto que tanto a anatomia quanto a fisiologia nasal destes animais se assemelha bastante com as características humanas.

Dentre os roedores estudados, os coelhos, as cobaias albinas e ratos Wistar e Sprague-Dawley se destacam, sendo as primeiras consideradas mais adequadas para estudos onde se exijam manipulação cirúrgica ou procedimentos invasivos, mas tendo alto grau de mortalidade quando mantidos em estresse e sendo os ratos considerados melhores para os estudos de médio e longo prazo, por serem mais resistentes. As cobaias ficam no meio termo entre um e outro.

Há procedimentos os mais diversos com o intuito de se obter uma inflamação nos seios paranasais similar aos processos de rinossinusites habituais.

Estudos sugerem desde manobras de obliteração das fossas nasais, obliteração dos óstios de drenagem sinusal, instilação de mediadores do processo inflamatório nos seios da face até a colocação de materiais que se prestem a meio de cultura nas fossas nasais.

Além desses métodos considerados assépticos, há estudos usando a inoculação in vivo de agentes infecciosos, fúngicos, bacterianos e virais ${ }^{1,2}$.

Entretanto, não se localiza na literatura estudos comparativos, com detalhamento do método e de des- crição morfológica e anatomopatológica, além de haver uma excessiva variedade de procedimentos para se obter o resultado inflamatório.

O fato de serem descritas muitas maneiras de se obter um resultado final, de não haver maiores esclarecimentos metodológicos e de não haver comparação entre estes métodos, obriga-nos a concluir que não temos informações suficientes para a confecção segura de experimentos em animais que exijam modelagem de rinossinusites, levando a maior chance de vieses de performance e dificuldade de controle.

Portanto, sugerimos neste estudo estabelecer um modelo experimental fidedigno, reproduzível e consistente para a rinossinusite inflamatória sem uso de inoculação de agentes infecciosos em coelhos.

\section{MATERIAL E MÉTODO}

O estudo foi realizado em biotério, em animais de experimentação, sob a supervisão veterinária, após aprovação do Comitê de Ética em Experimentação em Animais da Santa Casa de São Paulo, sob protocolo de №. 117.

Os animais estudados foram coelhos New Zealand, de 6 meses de idade e peso de 2,3 a $3,5 \mathrm{~kg}$, uma vez que apresentam estrutura anatômica do nariz semelhante a dos seres humanos e oferecem boas condições de manipulação, acompanhamento e avaliação.

Um total de 20 coelhos foi utilizado no estudo, tendo sido divididos em 4 grupos com 5 animais em cada. Cada grupo foi submetido a um procedimento diferente com o intuito de se obter uma resposta inflamatória controlada nos seios paranasais.

Todos os animais foram pesados antes do procedimento e diariamente até seu sacrifício. A quantidade de alimentação ingerida diariamente foi controlada. A temperatura auricular foi mensurada duas vezes ao dia.

Os animais foram avaliados quanto a alguns parâmetros clínicos que podiam indicar suas condições clínicas. Os parâmetros avaliados foram: aceitação da alimentação, peso e temperatura.

Os animais foram acompanhados até 15 dias do início do estudo e ao final do período de seguimento foram anestesiados e sacrificados.

\section{Procedimentos}

Os animais foram submetidos à anestesia geral previamente ao procedimento cirúrgico e mantidos sob ventilação espontânea.

Foram submetidos à medicação anestésica com Zoletil ${ }^{\circledR}$ na dose de $0,4 \mathrm{ml} / \mathrm{Kg}$ de peso aplicado por via intramuscular. Foram mantidos com anestesia e ventilação espontânea.

O espéculo nasal foi posicionado para a exposição da cavidade nasal do lado sorteado no momento do procedimento. 
Nos grupos 1 e 2, uma vez posicionado o espéculo, um spray de $0,8 \mathrm{ml}$ de xilocaína com epinefrina a $2 \%$ ® foi instilado na fossa nasal a ser manipulada e aguardamos 3 minutos para o início do procedimento.

De acordo com o grupo de intervenção, os animais foram submetidos a um dos seguintes procedimentos:

Grupo 1: Composto por 5 animais. Os animais desse grupo de estudo foram submetidos à inserção de esponja de banho recortada, com dimensões de $4 \mathrm{~cm}$ x $0,5 \mathrm{~cm}$ $\mathrm{x} 1 \mathrm{~cm}$ em uma das fossas nasais, decidida aleatoriamente por sorteio. O procedimento foi considerado encerrado quando nos certificamos da correta colocação da esponja e preenchimento de toda a fossa nasal.

Grupo 2: Composto por 5 animais. Os animais desse grupo de estudo foram submetidos à instilação de cianoacrilato em infundíbulo para obliteração de óstio nasossinusal, em uma das fossas nasais, decidida aleatoriamente por sorteio. O procedimento foi considerado encerrado quando verificamos a obliteração total do óstio.

Grupo 3: Composto por 5 animais. Os animais desse grupo de estudo foram submetidos à retirada de $1 \mathrm{ml}$ de sangue venoso periférico e instilação por punção percutânea em um dos seios maxilares, decidido aleatoriamente por sorteio. O procedimento foi considerado encerrado quando da instilação total do sangue no seio paranasal escolhido.

Grupo 4: Composto por 5 animais. Os animais desse grupo de estudo foram submetidos à instilação de $1 \mathrm{ml}$ de toxóide preparado laboratorialmente, contendo 50\% de toxóide estafilocócico e 50\% de toxóide estreptocócico, por punção percutânea em um dos seios maxilares, decidido aleatoriamente por sorteio. O procedimento foi considerado encerrado quando da instilação total dos antígenos no seio paranasal escolhido.

Em todas as intervenções, o seio maxilar e a fossa nasal não submetidos ao procedimento foram usadas como controle.

Após 15 dias de acompanhamento, os animais foram anestesiados e submetidos à eutanásia.

Neste momento, a meso-estrutura facial foi retirada em bloco e formolizada para estudo anatomopatológico posterior.

\section{Exame anatomopatológico}

Após congelamento dos blocos de meso-estrutura, foram estabelecidos cortes coronais seriados na distância de $3 \mathrm{~mm}$ da parede anterior do seio maxilar até sua parede posterior e estudado o padrão histológico do mesmo.

As lâminas foram preparadas por um único patologista e avaliadas por três profissionais habilitados de maneira cega quanto ao grupo a que o espécime pertencia.

Foram considerados parâmetros definidores de reação inflamatória qualitativos e quantitativos a presença de cachos de neutrófilos, de eosinófilos, de regiões com perda de células de revestimento, de células caliciformes e de células inflamatórias induzidas pela óxido nítrico sintetase (iNOS)-positivo.

\section{RESULTADOS}

Todos os animais do estudo desenvolveram rinorréia amarelada unilateral até o $15^{\circ}$ dia de acompanhamento.

A grande maioria teve uma discreta perda de peso no primeiro dia após o procedimento, evoluindo posteriormente com ganho de peso progressivo normal para o período.

A temperatura teve uma variação máxima de $0,8^{\circ} \mathrm{C}$ durante todo o período, não tendo caracterizado febre em nenhum animal.

O estudo anatomopatológico da meso-estrutura facial revelou, nos animais do grupo 1, processo inflamatório agudo intenso na cavidade nasal e seio maxilar, envolvendo corpo estranho amarelado fragmentado, que correspondia à esponja, com epitélio ulcerado e neoformação capilar no córion, caracterizando tecido de granulação (Figura 1).

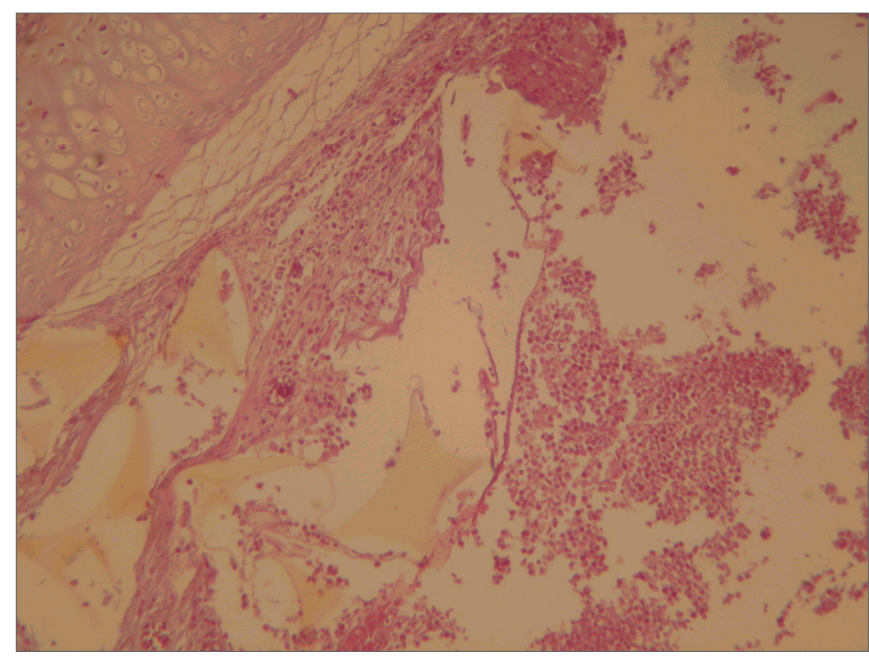

Figura 1. Mucosa de seio maxilar mostrando processo infecto-inflamatório moderado para intenso e presença de corpo estranho (esponja). Coloração HE, 40X.

Nos animais do grupo 2, o relato dos patologistas revelou processo inflamatório agudo purulento moderado, com macrófagos de permeio na cavidade nasal e seio maxilar, envolvendo corpo estranho filamentoso e róseo claro, que correspondia ao cianoacrilato, com ulceração epitelial e neoformação capilar e infiltrado linfoplasmocitário no córion (Figura 2). No grupo 3, a análise de três animais revelou processo inflamatório agudo purulento discreto e algumas hemácias na cavidade nasal e seio maxilar. Em dois animais desse grupo só foi relatado presença de hemácias na cavidade nasal e luz do seio maxilar, sem referência a processo inflamatório. Na análise do grupo 4 , todas as descrições referiram processo inflamatório agudo 
purulento discreto e hemácias na cavidade nasal e luz do seio maxilar. Em todos os animais, foi utilizado o lado contralateral como controle e não foi descrita nenhuma alteração inflamatória nessas peças.

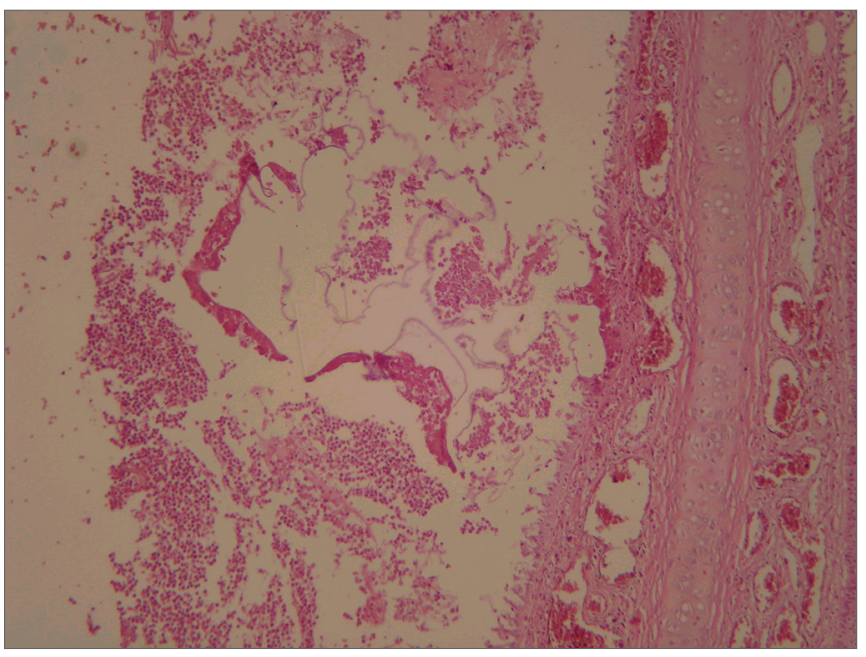

Figura 2. Corte transversal de mucosa de seio maxilar de coelho mostrando intensa reação inflamatória, com acúmulo de fibrina e hemácias no entorno, o material amorfo representa a cola, Coloração HE, 40X.

\section{DISCUSSÃO}

$\mathrm{Na}$ literatura estão disponíveis inúmeros trabalhos que estudam as alterações mais freqüentes da mucosa nasossinusal acometida por um processo inflamatório e os principais aspectos de seu tratamento. Também é amplamente discutido qual deve ser o modelo de pesquisa utilizado nesses estudos, levando em conta o animal a ser utilizado e os meios para provocar a rinossinusite. Estamos desenvolvendo alguns estudos nessa área, na tentativa de padronizar um modelo experimental de rinossinusite, com metodologia detalhada, para eliminar a possibilidade de viés nessas pesquisas.

Os diversos autores que desenvolvem pesquisa nessa área utilizam meios variados para confecção dos modelos. Alguns introduzem cepas de bactérias patogênicas no interior do seio da face, associado ou não a um bloqueio do óstio de drenagem. Este tipo de enfoque, apesar de eficiente, leva a dificuldades operacionais, pois necessita de ambiente protegido para a manipulação de espécies patogênicas, o que inviabiliza o seu empregos em unidades de pesquisa menos aparelhadas.

Cable $(2000)^{3}$, em seu estudo sobre a eficácia de corticosteróides no tratamento de rinossinusite, introduziu cirurgicamente cepas de Pseudomonas em seios paranasais de coelhos. Stierna (1991) ${ }^{4}$ comparou as alterações patológicas da mucosa sinusal de coelhos quando inoculada secreção de Streptococcus pneumoniae e Bacteróides fragilis, após o bloqueio do óstio maxilar. Observou al- terações mais intensas e pronunciadas nas mucosas em que foi instilada a secreção de Bacteróides. Nestas, além das alterações já esperadas de um processo inflamatório, observou adelgaçamento do periósteo, neoformação óssea, rinorréia mais pronunciada, com maior nível de lactato, indicando metabolismo anaeróbio. Westrin (1992) induziu sinusite em coelhos, bloqueando o óstio do seio e inoculando solução de Bacteroides fragilis. Também concluiu que os danos inflamatórios são maiores quando comparados à infecção causada por pneumococo.

No estudo de Maeyama (1981) foi utilizada solução de Staphylococcus, por instilação percutânea. Após duas semanas, verificou-se o desenvolvimento de sinusite em alta incidência, através de microscopia eletrônica e análise histológica. Johansson (1988) utilizou um modelo de coelhos semelhante ao nosso, obstruindo o óstio e instilando $1 \mathrm{ml}$ de toxóide de Streptococcus no interior do seio. Observou o desenvolvimento de sinusite em todos os animais. Em outros dois grupos, em que foi bloqueado o óstio isoladamente ou instilado toxóide em seio com óstio pérvio, não houve desenvolvimento de infecção. Estes resultados estão em desacordo com nossos achados, pois tivemos uma grande taxa de rinossinusite nos coelhos com a inoculação de toxóide, mesmo com o óstio aberto.

No estudo de Kara $(2002)^{8}$, utilizando coelhos, a sinusite só se desenvolveu nos animais que tiveram o óstio maxilar obstruído com esponja hemostática absorvível embebida em solução de Staphylococcus. No grupo em que foi apenas obstruído o óstio, com esponja estéril, não se desenvolveu a patologia, até a vigésima semana de observação. No ano de 2003, esse mesmo autor publicou uma revisão da metodologia de desenvolvimento do modelo de sinusite em coelhos, onde defende que este é um modelo fidedigno à patologia em humanos. Também este estudo não alcançou os mesmos resultados que o nosso, visto que a simples obstrução da fossa nasal com esponja foi suficiente para produzir o modelo?.

Marks $(1997)^{10}$, em uma tentativa de padronizar um modelo de sinusite bacteriana em coelhos, introduziu um corpo estranho na cavidade nasal, em seguida instilou solução de bactérias patogênicas, também na fossa nasal. Observou o desenvolvimento de sinusite em 50\% dos animais, com pico de intensidade da reação inflamatória até a segunda semana, quando esta diminui progressivamente até a quarta semana, quando já se observam alterações patológicas crônicas na mucosa. Este tipo de estudo de maior duração deve ser repetido por nós, visto que os autores não conseguiram a manutenção do processo inflamatório por muito tempo, o que poderia inviabilizar o uso do modelo para estudos mais longos. Drettner $(1987)^{11}$ desenvolveu um modelo de sinusite em coelhos através da exposição cirúrgica do seio maxilar, bloqueio do óstio nasal e introdução de colônias de Streptococcus pneumoniae. Após 4 dias, as colônias foram retiradas e 
os seios maxilares avaliados histologicamente. Observou adelgaçamento da mucosa do seio, dilatação de vênulas, aumento do fluxo sangüíneo e infiltração de granulócitos. Não evidenciou presença de bactérias na mucosa.

Na tentativa de padronização do modelo de sinusite fúngica em coelhos, Dufor (2005) ${ }^{12}$, concluiu que se pode induzir sinusite através do bloqueio do óstio e inoculação de cepas do fungo no interior do seio. No grupo em que não foi bloqueado o óstio, não houve desenvolvimento de patologia, apesar da inoculação do fungo.

Cetin (2002) ${ }^{13}$ comprovou o desenvolvimento de rinossinusite provocada por cateterização da fossa nasal de coelhos. Procedeu a cateterização e analisou os animais no final da primeira, segunda e quarta semanas, através de imagem de tomografia computadorizada, análise microbiológica e histopatológica. Concluiu que a cateterização da fossa nasal é um fator predisponente de rinossinusite, sendo potencializado pelo tempo mais longo de permanência da sonda e calibre mais grosso desta.

Hinni $(1992)^{14}$ avaliou as alterações funcionais precoces - até o $5^{\circ}$ dia - da mucosa sinusal através da obstrução do óstio e inoculação de cepas das bactérias mais comumente envolvidas nesses processos inflamatórios. Encontrou uma diminuição de células ciliadas e correspondente alteração da atividade mucociliar, dependente do microorganismo envolvido, sendo esse um importante fator predisponente ao desenvolvimento de sinusite aguda.

Hurley $(2001)^{15}$, em seu estudo de análise quantitativa de leucotrienos, criticou e apontou falhas no modelo de sinusite maxilar em coelhos, utilizado amplamente desde os anos 80. Afirma que o modelo não reproduz com fidelidade a patologia em humanos, devido às bactérias comumente envolvidas nas infecções humanas não serem tão patogênicas em coelhos. Afirma também que o seio maxilar do modelo é muito pequeno, o que limita a obtenção de material para análise. Essa opinião é controversa à publicada por Kara' .

Todos estes estudos mostram que há diversas maneiras de se estabelecer um modelo experimental de rinossinusite, entretanto as variáveis são em grande número. Consideramos que a possibilidade de se estabelecer um modelo barato e de fácil execução, com o uso de material acessível seja fundamental para a experimentação em nosso meio.

Nosso estudo conseguiu atingir resultados semelhantes ao da literatura com procedimentos apropriados à nossa realidade com consistência suficiente do ponto de vista histológico.

A utilização de esponja e toxóide parece ter a melhor lógica e confiabilidade e pretendemos aprofundar nossa investigação estudando esta associação por um período de tempo maior.

\section{CONCLUSÃO}

Concluímos que é possível padronizar um modelo de rinossinusite em coelhos, com um período de observação de 15 dias. Dentre os quatro métodos utilizados, obtivemos um processo inflamatório mais intenso após a introdução de esponja preenchendo a fossa nasal enquanto o uso de sangue na cavidade produziu pouca reação inflamatória.

\section{REFERÊNCIAS BIBLIOGRÁFICAS}

1. Schenkel, EP, Simões, CMO, Mengue SS, Mentz, LA, Irgang, BE, Stehmann, JR. O espaço das plantas medicinais e suas formas derivadas na medicina científica. Caderno de Farmácia 1985;1:65-72.

2. Krouse JH, Krouse HJ. Patient use of traditional and complementary therapies in treating rhinosinusitis before consulting an otolaryngologist. Laryngoscope 1999;109:1223-7.

3. Cable BB, Wassmuth Z, Mann EA, Hommer D, Connely G, Klem C, Quance-Fitch FJ, Bolger WE. The effect of corticosteroids in the treatment of experimental sinusitis. Am J Rhinol 2000; 14(4):217-22.

4. Stierna P, Kumlien J, Carlsoo B. Experimental sinusitis in rabbits induced by aerobic and anaerobic bacteria: models for research in sinusitis. J Otolaryngol 1991;20(6):376-8.

5. Westrin KM, Norlander T, Stierna P, Carlsoo B, Nord CE.Experimental maxillary sinusitis induced by Bacteroides fragilis. A bacteriological and histological study in rabbits. Acta Otolaryngol 1992;112(1):10714.

6. Maeyama T. A study of experimental sinusitis in rabbits. Auris Nasus Larynx 1981;8(2):87-97.

7. Johansson P, Kumlien J, Carlsoo B, Drettner B, Nord CE. Experimental acute sinusitis in rabbits. A bacteriological and histological study. Acta Otolaryngol $1988 ; 105(3-4): 357-66$.

8. Kara CO, Cetin CB, Colakoglu N, Sengul M, Pakdemirli E. Experimentally induced rhinosinusitis in rabbits. J Otolaryngol 2002 ;31(5):2948.

9. Kara CO, Demirkan N. A review on experimental sinusitis models in rabbits. Kulak Burun Bogaz Ihtis Derg 2003 Mar;10(3):122-30.

10. Marks SC.Acute sinusitis in the rabbit: a new rhinogenic model. Laryngoscope 1997 Dec;107(12 Pt 1):1579-85.

11. Drettner B, Johansson P, Kumlien J. Experimental acute sinusitis in rabbit. A study of mucosal blood flow. Acta Otolaryngol 1987 ;10366):432-4.

12. Dufour X, Kauffmann-Lacroix C, Goujon JM, Grollier G, Rodier MH, Klossek JM. Experimental model of fungal sinusitis: a pilot study in rabbits. Ann Otol Rhinol Laryngol 2005 Feb;114(2):167-72.

13. Cetin CB, Kara CO, Colakoglu N, Sengul M, Pinar HS. Experimental sinusitis in nasally catheterised rabbits. Rhinology 2002;40(3):154-8.

14. Hinni ML, McCaffrey TV, Kasperbauer JL. Early mucosal changes in experimental sinusitis. Otolaryngol Head Neck Surg 1992; 107(4):53748.

15. Hurley DB, Smith GS, Vogler GA, Desponde Y, Citardi MJ. Leukotriene B4 levels in rabbit maxillary sinusitis: limitations of the current model. Am J Rhinol 2001;15(1):47-8. 